\title{
Numerical investigation of tide and sea level anomalies propagation in Malacca Strait
}

\author{
Alamsyah Kurniawan ${ }^{1, *}$, Serene Hui Xin Tay ${ }^{2}$, and Seng Keat Ooi ${ }^{2}$ \\ ${ }^{1}$ Ocean Engineering Program, Institut Teknologi Bandung, Indonesia \\ ${ }^{2}$ Tropical Marine Science Institute, National University of Singapore, Singapore
}

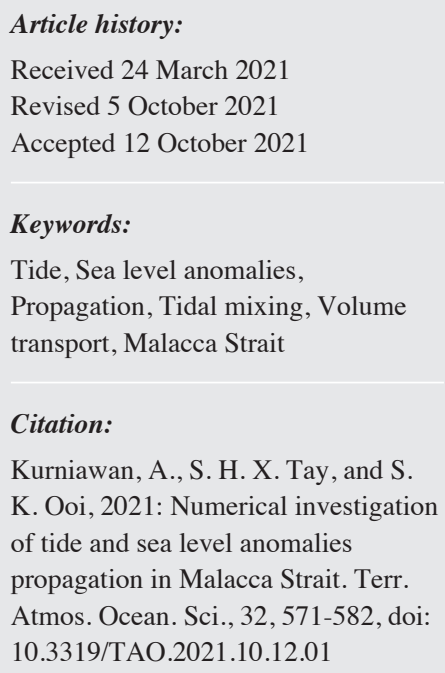

\begin{abstract}
The importance of the Malacca Strait to trade is important but its importance in terms of ocean connectivity is often ignored. This paper is a study of the propagation of tide and sea level anomalies (SLA) (i.e., non-tidal component) in the Malacca Strait using a well calibrated numerical model. Four main tidal constituents are examined at different sections of the strait. Tidal amplitude in terms of water level and volumetric flux of these four constituents are derived using harmonic analysis. It is shown that the tidal flux propagation pattern behaves differently from the tidal water level propagation pattern in the strait. Detailed analysis of the tidal amplitudes of both water level and volumetric flux makes the location of the tidal mixing zone in the strait becomes apparent. Analyzing the SLA with regards to flux and net flux volume at each cross section in the strait shows that the tidal mixing zone plays a role in obstructing the propagation of SLA from Andaman Sea and Singapore Strait.
\end{abstract}

\section{INTRODUCTION}

Historically the Malacca Strait has been an important trade route linking Indian to South China Sea and Pacific Ocean for many centuries. Notwithstanding its maritime history, Malacca Strait is also an area with rich resources including productive coastal ecosystems, mangrove forests, coral reefs, seagrass beds, and fisheries (Thia-Eng et al. 2000). Located between the Andaman Sea and the South China Sea, Malacca Strait is hydrodynamically complex due to the confluence of tides from these two large water bodies with seasonal monsoons that have effect on the net flow transport through the strait (Rizal et al. 2010; Van Maren and Gerritsen 2012; Kurniawan et al. 2014, 2015; Tay et al. 2016). In this paper, the flow condition is defined by a combination of tidal and non-tidal.

Tidal flow variations are deterministic, and their corresponding amplitude and phase can be obtained using harmonic analysis (Pugh 1996). Tidal dynamics in this region have been discussed in Kurniawan et al. (2011), Van Maren

\footnotetext{
* Corresponding author

E-mail:alamsyah@ocean.itb.ac.id
}

and Gerritsen (2012), and Tay et al. (2016). The tidal range in Malacca Strait varies between 1.6 and $3.7 \mathrm{~m}$, and in certain areas along the east coast of Sumatra, the tidal range can be as much as 4 to $5 \mathrm{~m}$ (Thia-Eng et al. 2000). The spatial tidal amplitude of semidiurnal tides over the strait is known to be highly varying in which $\mathrm{M}_{2}$ amplitude ranges between 0.5 and $1.5 \mathrm{~m}$ within the $900 \mathrm{~km}$ long strait (Rizal and Sündermann 1994; Kurniawan et al. 2015). Van Maren and Gerritsen (2012) highlighted the complexity of tidal and subtidal flows around the region, with substantial subtidal flows generated by residuals and low frequency currents with periodicities of 2 weeks to 1 year. Recently, there has been interest in ocean renewable energy extraction in Malacca Strait whereby exploration of harvesting technologies and potential sites in the strait are studied (Chong and Lam 2013; Bonar et al. 2018). Considering the strong tidal movement in the strait, tidal energy could be a potential ocean renewable energy source.

Non-tidal flow is captured as Sea Level Anomalies (SLA) defined as variation of sea level from deterministic tidal variation. SLA, which is the resultant of non-tidal 
forcing in this region, has been studied using both long term in-situ gauge measurement data analysis (Luu et al. 2015) and numerical modelling to represent SLA accurately (Kurniawan et al. 2014; Tay et al. 2016). Studies related to water physical and biochemical properties such as temperature, salinity, dissolved oxygen, chlorophyll-a in the strait have been carried to infer the possible dynamics in relation to the local water mass transport (Hii et al. 2006; Ibrahim and Yanagi 2006; Tan et al. 2006; Amiruddin et al. 2011). Originating or triggering mechanism of SLA in the region has been studied by Kurniawan et al. (2015) and Tay et al. (2016), in which the SLA in Singapore Strait is found to be mostly influenced by wind and air pressure in South China Sea, and SLA in Malacca Strait is induced by SLA originating in the northeastern part of Indian Ocean. Seasonal flux transport through the strait has been described qualitatively in Tay et al. (2016) which showed that the net flow in Malacca Strait is southeastward (towards Singapore Strait) from May to September and westward (towards Andaman Sea) from November to March. However, the volume transport through the strait was only studied at one section in the strait. Considering high variation of tidal amplitudes in the strait, the net flow in one section may not be representative for the entire strait. It has also been noted by Kurniawan et al. (2015) and Tay et al. (2016) based on in-situ gauge measurement and numerical modelling, the SLA propagation through the strait could be hindered by the local tidal mixing zone which is located in the south, close to Singapore Strait (Chen et al. 2005).

Propagation and amplification of tide have been known to affected by bottom friction, bathymetry and land mass geometry (Friedrichs and Aubrey 1994; Van Rijn 2011; Chen et al. 2014). Previous studies of Malacca Strait have mainly focused on water level to study to propagation of tide and SLA. To the authors' knowledge there are no studies that describe the propagation of tidal and non-tidal (SLA associated) in terms of volume transport across each section or zone in Malacca Strait. Therefore, the first part of this paper will attempt to study the tidal propagation and the tidal waves interaction using a well-calibrated numerical model to estimate the tidal mixing zone in the strait based on flow rate and flux across sections of the strait. The second part of the paper will focus on the propagation of SLA with its associated volume transport and assess the impact of the local tidal mixing zone on SLA propagation in Malacca Strait.

\section{METHODOLOGY}

To simulate propagation of tide and sea level anomalies in Malacca Strait, the so-called Singapore Regional Model (SRM) is used. The SRM is built in the Delft3D modelling environment (Lesser et al. 2004). This model has been extensively calibrated using data assimilation approach and satellite altimetry dataset by Kurniawan et al. (2011).

\subsection{Model Setup}

The model extends from 95 to $109^{\circ} \mathrm{E}$ and $4^{\circ} \mathrm{S}$ to $10^{\circ} \mathrm{N}$, stretching from northern Sumatra to the eastern coast of Borneo. SRM has open boundaries on the Andaman Sea, Java Sea and the South China Sea at which tidal constituents are input for tidal forcing of the model (Fig. 1). To accurately account for the tidal predictions, the model open boundaries are prescribed as water level by means of amplitude and phases (relative to time zone GMT+8) of the eight main tidal components $\mathrm{Q}_{1}, \mathrm{O}_{1}, \mathrm{P}_{1}, \mathrm{~K}_{1}, \mathrm{~N}_{2}, \mathrm{M}_{2}, \mathrm{~S}_{2}$, and $\mathrm{K}_{2}$. The numerical model solves the $2 \mathrm{D}$ depth averaged shallow water flow equations. It features a boundary-fitted curvilinearspherical orthogonal grid which consists of around 38500 horizontal grid cells, and the sizes of the grid cells vary from approximately 200 to $300 \mathrm{~m}$ around Singapore Island to approximately $15 \mathrm{~km}$ at the open sea boundaries. The model bathymetry is based on Admiralty charts and the depths range from maximum about $2000 \mathrm{~m}$ in the Andaman Sea to approximately $40-50 \mathrm{~m}$ depth around Singapore Strait.

\subsection{Tidal Model Validation}

Previously in Kurniawan et al. (2011), the model has been calibrated for tide using summed vector difference based on tidal constituents amplitude and phase for 77 locations (Naeije et al. 2006), of which 26 are located in Malacca Strait. As this paper focuses on Malacca Strait, therefore model validation is carried out using a separate set of data which is based on local observation along the coast of Sumatra. The observation location is presented in Fig. 1. Tidal dataset is taken from tide table in which tidal prediction is computed based on the Admiralty method using harmonic constant taken from the Indonesian Sailing Direction and the results of the Hydro-Oceanographic surveys (http:// www.pushidrosal.id/). As the tidal dataset is in the form of water level time series, model validation is carried out based on root mean square error (RMSE) or root mean squared difference (RMSD) and correlation coefficient [see Eqs. (1) and (2)].

$\operatorname{RMSE}$ or $\mathrm{RMSD}=\sqrt{\frac{\sum_{t=1}^{N}\left(x_{t}-y_{t}\right)^{2}}{N}}$

Correlation coefficient $=\frac{\sum_{t=1}^{N}\left(x_{t}-\bar{x}\right)\left(y_{t}-\bar{y}\right)}{\sqrt{\sum_{t=1}^{N}\left(x_{t}-\bar{x}\right)^{2}} \sqrt{\sum_{t=1}^{N}\left(y_{t}-\bar{y}\right)^{2}}}$

where $x$ and $y$ represent observation and model result, respectively, at time instance $t$ with $N$ as total number of time instances of recorded data, with their mean value $x$ and $y$.

Table 1 presents the RMSE and correlation coefficient of modelled water level compared to tidal dataset at 14 stations over the period of one month (1 April to 1 May 2017). 


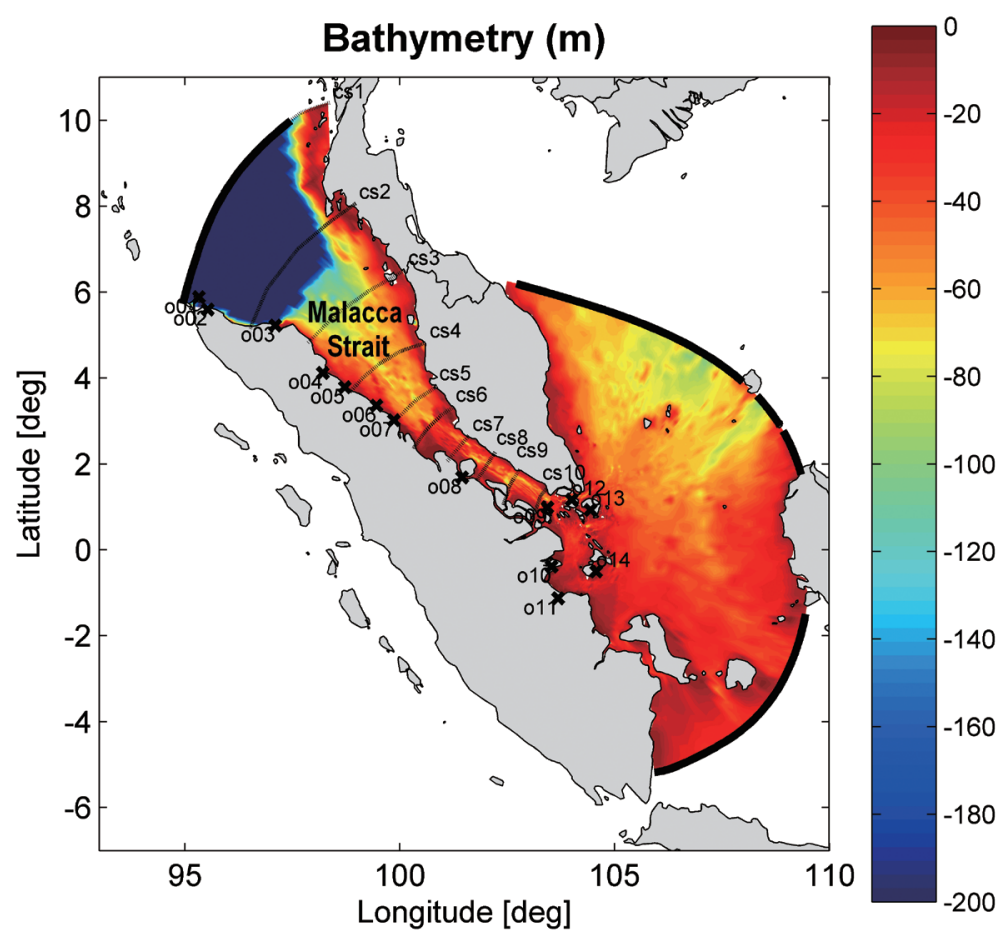

Fig. 1. Singapore Regional Model (SRM) showing bathymetry (in meters) and open boundary location (black solid lines, where tidal forcing are prescribed). The " $\mathrm{x}$ " denotes observation locations used for model validation. Zoning of Malacca Straits partitioned by 10 cross sections (black dash lines).

Table 1. Model validation at 14 Indonesian coastal stations in Malacca Strait.

\begin{tabular}{cccccc}
\hline Station ID & Station Name & Longitude (degree) & Latitude (degree) & RMSE $(\mathbf{m})$ & Correlation coefficient \\
\hline o01 & Sabang & 95.32167 & 5.88167 & 0.134 & 0.951 \\
o02 & Malahayati & 95.52568 & 5.59738 & 0.133 & 0.947 \\
o03 & Lhokseumawe & 97.10167 & 5.22167 & 0.140 & 0.966 \\
o04 & Pangkalansusu & 98.20833 & 4.12056 & 0.209 & 0.939 \\
o05 & Belawan & 98.71583 & 3.78556 & 0.151 & 0.966 \\
o06 & Kualatanjung & 99.45361 & 3.35750 & 0.134 & 0.983 \\
o07 & Muara Sungai Asahan & 99.86056 & 3.01833 & 0.229 & 0.969 \\
o08 & Dumai & 101.44833 & 1.68722 & 0.300 & 0.929 \\
o09 & Tanjungbalai Karimun & 103.43499 & 0.98827 & 0.241 & 0.959 \\
o10 & Indragiri & 103.53056 & -0.38639 & 0.335 & 0.919 \\
o11 & Muara Sabak & 103.68364 & -1.12819 & 0.267 & 0.963 \\
o12 & Batuampar & 104.00206 & 1.16503 & 0.216 & 0.965 \\
o13 & Tanjungpinang & 104.43939 & 0.93080 & 0.235 & 0.927 \\
o14 & Dabosingkep & 104.56857 & -0.50279 & 0.201 & 0.953 \\
\hline
\end{tabular}


It is shown that the range of RMSE is 0.133 and $0.335 \mathrm{~m}$. These results can be argued as the lowest RMSE location is near boundary whereas the highest is located in the mid of Malacca Strait. The relatively high RMSE value (above $0.2 \mathrm{~m}$ ) can be explained with respect to the relatively coarse grid resolution around the coastal area where the tidal station is located. However, since high correlation coefficient, above 0.90 , is noted for all stations, the model is deemed suitable to simulate propagation of tide in Malacca Strait.

\section{RESULTS AND DISCUSSION}

As the model has shown to be validated for Malacca Strait in the previous chapter, this chapter will attempt to investigate the tidal propagation and mixing as well as SLA propagation in Malacca Strait. The model is simulated for one year from 1 January to 31 December 2011. It is noted that the first 10 days of the simulation is assumed to be model spin-up and only the results after the spin-up is used for analysis.

\subsection{Tidal Propagation and Mixing}

In this paper, the strait is divided into 9 zones partitioned by 10 cross sections (Fig. 1). This zoning of the strait is referenced to the so-called blocks used for model calibration in Kurniawan et al. (2011), in which sensitivity tests on variation of depth and friction are carried out. The cross sections are named in running numbers from cs 1 to cs 10 in which cs1 is the northwestern end near Andaman Sea and cs10 is the southwestern end near Singapore Strait. Table 2 presents the width, area and geographical location of each cross sections. It is noted that cs 1 and cs 2 are located in areas where the Sunda Shelf breaks in front of the Andaman Sea, where the depths are more than $1000 \mathrm{~m}$ deep, which explains the very large cross-sectional area compared to the others. Based on the model results, the propagation of tidal wave through each cross section will be analyzed in this paper.

Following Haditiar et al. (2020), the tidal water level timeseries (see Fig. 2 for an example of the tidal water level timeseries at the centre of $\operatorname{cs} 7$ ) at the centre of each cross

Table 2. Width and area of each cross section in Malacca Strait.

\begin{tabular}{ccccc}
\hline Cross section & Width $(\mathbf{k m})$ & Area $\left(\mathbf{k m}^{2}\right)$ & Longitude of centre point (degree) & Latitude of centre point (degree) \\
\hline cs1 & 671.1 & 595.240 & 96.037 & 8.281 \\
cs2 & 412.3 & 266.379 & 97.554 & 7.078 \\
cs3 & 300.0 & 19.470 & 98.728 & 5.754 \\
cs4 & 233.2 & 10.545 & 99.630 & 4.454 \\
cs5 & 137.1 & 6.321 & 100.328 & 3.474 \\
cs6 & 137.0 & 2.843 & 100.748 & 3.007 \\
cs7 & 73.1 & 1.875 & 101.384 & 2.430 \\
cs8 & 80.9 & 2.181 & 102.050 & 1.947 \\
cs9 & 69.3 & 1.890 & 102.603 & 1.595 \\
cs10 & 45.6 & 1.314 & 103.214 & 1.293 \\
\hline
\end{tabular}

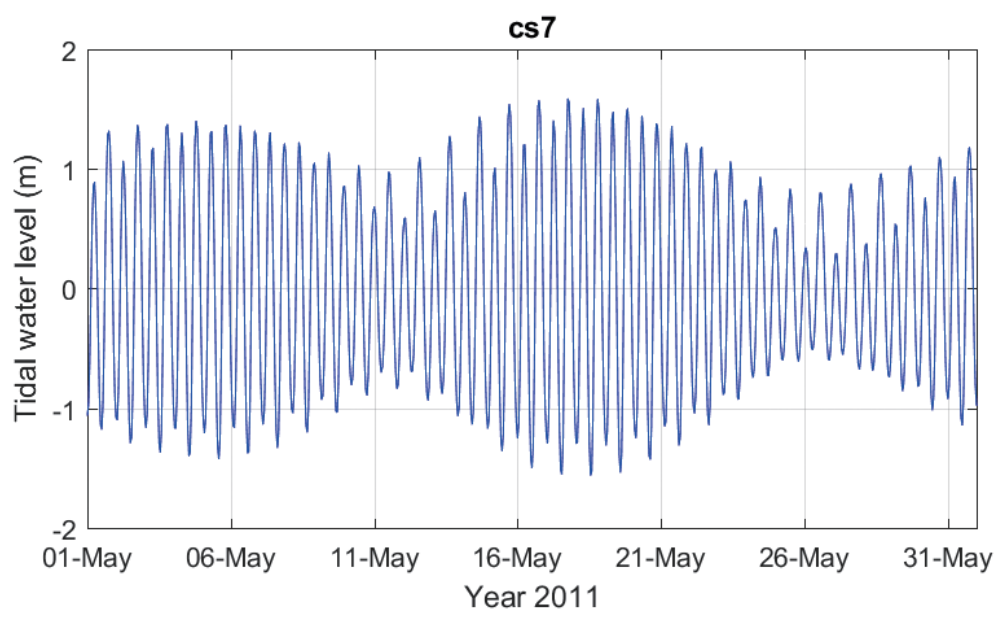

Fig. 2. One-month simulated tidal water level at centre of cross section cs7. 
section (cs1 to cs10) (Table 2) is analyzed using harmonic analysis to derive the amplitude and phase of four main tidal constituents $\mathrm{M}_{2}, \mathrm{~S}_{2}, \mathrm{~K}_{1}$, and $\mathrm{O}_{1}$ (Table 3 ). Figure 3 presents the co-tidal map of $\mathrm{M}_{2}, \mathrm{~S}_{2}, \mathrm{~K}_{1}$, and $\mathrm{O}_{1}$.

Looking at the phase values in Table 3 and the co-tidal maps, $\mathrm{M}_{2}, \mathrm{~S}_{2}$, and $\mathrm{K}_{1}$ tide in Malacca Strait propagates southeastward (from Andaman Sea to Singapore Strait), and only $\mathrm{O}_{1}$ tide propagates in the reverse direction i.e., northwestward. The $\mathrm{M}_{2}$ and $\mathrm{S}_{2}$ speed propagation speed is consistent from cs 2 to cs 10 . In contrast, $\mathrm{K}_{1}$ propagation speed is low between cs 2 and cs6, increases significantly between cs6 and cs8, and slows down again between cs8 and cs10. Coming from Singapore Strait in the opposite direction, $\mathrm{O}_{1}$ propagates slowly between cs 10 and cs7, speeds up between cs 7 and cs5, and slows down again between cs5 and cs 2 .

Figure 4 presents the tidal water level amplitude of the tidal constituents at the centre of each cross section. Propagating in the same direction, both $\mathrm{M}_{2}$ and $\mathrm{S}_{2}$ tides share the same amplitude variation pattern in Malacca Strait; both start with relatively low values from cs 1 to cs 4 , increases from cs 4 to cs 6 where they peak, and decreases as they propagate southeastward until cs8 and slowly increases again from cs8 to cs10. Amplitude of $\mathrm{K}_{1}$, on the other hand, increases from cs 1 to cs5 where it peaks, and decreases to its minimum at cs7 and increases again as it propagates towards cs 10 . In the reverse direction, high amplitude $\mathrm{O}_{1}$ propagates from cs 10 to $\operatorname{cs} 8$, and decreases significantly from cs 8 to cs6, and remain low till cs 1 . Interestingly, significant changes in amplitude or phase of the tides mostly occur in the zone between cs6 and cs8, in which cs7 has the smallest crosssectional area and is also the narrowest among three.

Figure 5 presents the current vector field in Malacca Strait during flood and ebb tides, respectively. It can be shown that the flow direction across each cross section is mostly uniform and perpendicular to each corresponding cross section at all sections except cs1 and cs2 where the depth varies between $100 \mathrm{~m}$ and above $1000 \mathrm{~m}$ along the cross section. These findings are comparable with Haditiar et al. (2020) (see Figs. 14a and b). The uniformity of the flow direction through each cross section in the shallow and narrow areas i.e., cs3 to cs10, allows us to assess the flow rate across these cross sections directly using harmonic analysis which was use earlier for tidal water level to derive the amplitude and phase of each tidal constituent. As for cs 1 and cs2 where the flow direction along the section is not uniform, it may not be suitable to analyze the flow rate across the entire cross section of cs 1 and cs 2 directly, and will be excluded from the subsequent analysis related to flow rate and flux.

Tide is often characterized in terms of the tidal constituent amplitude based on water level time series using harmonic analysis. Same approach of harmonic analysis can be applied on flow rate in cubic meter per second $\left(\mathrm{m}^{3} \mathrm{~s}^{-1}\right)$ through cross section (see Fig. 6 for an example of the tidal flow rate time series at cs7) which is a model output. The tidal dynamics in Malacca Strait can be characterized based flow rate through each cross section in the strait using harmonic analysis. This will determine the flow rate amplitude of each tidal constituent through each section of the strait as presented in Fig. 7. The flow rate amplitude of all four constituents is the highest at section cs1 where the cross section is the largest among all in terms of area and reduces as it approaches southeastward where the strait narrows (Fig. 7).

As the flow rate is defined as the volume of water passing through a particular cross section per second, it is proportional to the cross-sectional area of that particular cross section. In order to evaluate the contribution of flow rate induced by each tidal constituent through the strait, the volumetric flux is used and is computed by dividing the flow rate through each section by the corresponding cross-sectional area [see Eq. (3)].

Flux $_{\text {CrossSection }}=$ FlowRate $_{\text {CrossSection }} /$ Area $_{\text {CrossSection }}$

Figure 8 presents the volumetric flux which is of the unit $\mathrm{m}^{3} \mathrm{~m}^{-2} \mathrm{~s}^{-1}$ depicting the flow rate amplitude per unit area per unit time of tidal constituent $\mathrm{M}_{2}, \mathrm{~S}_{2}, \mathrm{O}_{1}$, and $\mathrm{K}_{1}$. The flux amplitude of all four tidal constituents are relatively low (less than $0.03 \mathrm{~m}^{3} \mathrm{~m}^{-2} \mathrm{~s}^{-1}$ ) at cs 1 and $\mathrm{cs} 2$ which are in the northwestern end of the strait near Andaman Sea. The dominant $\mathrm{M}_{2}$ flux amplitude increases steadily southeastward from cs2 $\left(0.02 \mathrm{~m}^{3} \mathrm{~m}^{-2} \mathrm{~s}^{-1}\right)$ to $\operatorname{cs} 6\left(0.51 \mathrm{~m}^{3} \mathrm{~m}^{-2} \mathrm{~s}^{-1}\right)$ which is more than 25 times and remain above $0.45 \mathrm{~m}^{3} \mathrm{~m}^{-2} \mathrm{~s}^{-1}$ from cs6 to cs 10 towards Singapore Strait. The $S_{2}$ flux amplitude along the strait shows similar trend as $\mathbf{M}_{2}$ but with half of $\mathbf{M}_{2}$ flux amplitude. The diurnal tidal flux amplitude is relatively smaller than the semi-diurnal tides with maximum of 0.2 and $0.14 \mathrm{~m}^{3} \mathrm{~m}^{-2} \mathrm{~s}^{-1}$ for $\mathrm{K}_{1}$ and $\mathrm{O}_{1}$, respectively.

Both semi-diurnal tide $\mathrm{M}_{2}$ and $\mathrm{S}_{2}$ have a single local peak flux amplitude which occurs around cs7. The diurnal tide $\mathrm{K}_{1}$ and $\mathrm{O}_{1}$, on the other hand, have two local peak flux amplitudes in the strait. For $\mathrm{K}_{1}$ tide, one occurs at $\mathrm{c} 7$ and another at cs3, though the latter is low (about $0.06 \mathrm{~m}^{3} \mathrm{~m}^{-2} \mathrm{~s}^{-1}$ ). The two local peak flux amplitudes of $\mathrm{O}_{1}$ tide occur at cs 7 and cs10 where both are of about $0.14 \mathrm{~m}^{3} \mathrm{~m}^{-2} \mathrm{~s}^{-1}$. As explained earlier, the diurnal $\mathrm{O}_{1}$ tide in this area is mainly from South China Sea through Singapore Strait (see Fig. 3), near cs10. In order words, as the $\mathrm{O}_{1}$ tide propagates from Singapore Strait into Malacca Strait via cs10 and further northwestward towards Andaman Sea, the $\mathrm{O}_{1}$ tide maintain their influence from cs 10 to cs 7 and begin to deteriorate beyond cs7 towards cs1. The semi-diurnal tides, on the other hand, propagate from Andaman Sea and gain influence between cs1 and cs7 as they propagate southeastward, and maintain their influence till they approach Singapore Strait. Propagating in the same direction (southeastward), $\mathrm{K}_{1}$ gains its influence from cs 2 to cs7 and slowly deteriorates beyond cs7 as it approaches Singapore Strait. 
Table 3. Water level amplitude (m) and phase (degree) $($ GMT +8$)$ of four main tidal constituents at the centre of each cross section (numbers in bold indicate distinctive features or anomalies which are described and highlighted in the text).

\begin{tabular}{c|cc|cc|cc|cc}
\hline \multirow{2}{*}{ Cross section } & \multicolumn{2}{|c|}{$\mathbf{M}_{\mathbf{2}}$} & \multicolumn{2}{c|}{$\mathbf{S}_{\mathbf{2}}$} & \multicolumn{2}{c|}{$\mathbf{K}_{\mathbf{1}}$} & \multicolumn{2}{c}{$\mathbf{O}_{\mathbf{1}}$} \\
\cline { 2 - 9 } & Amplitude & Phase & Amplitude & Phase & Amplitude & Phase & Amplitude & Phase \\
\hline cs1 & 0.54 & 47 & 0.26 & 115 & 0.12 & 44 & 0.06 & 341 \\
cs2 & 0.56 & 49 & 0.28 & 118 & 0.13 & 42 & 0.06 & 335 \\
cs3 & 0.59 & 82 & 0.31 & 153 & 0.18 & 50 & 0.07 & 330 \\
cs4 & 0.55 & 162 & 0.29 & 231 & 0.23 & 60 & 0.06 & 323 \\
$\operatorname{cs5}$ & 1.02 & 219 & 0.50 & 293 & 0.24 & 70 & 0.04 & $\mathbf{3 0 1}$ \\
$\operatorname{cs6}$ & $\mathbf{1 . 2 1}$ & 241 & $\mathbf{0 . 5 8}$ & 317 & 0.21 & $\mathbf{7 8}$ & $\mathbf{0 . 0 4}$ & $\mathbf{2 3 9}$ \\
$\operatorname{cs} 7$ & 1.00 & 283 & 0.47 & 2 & $\mathbf{0 . 0 7}$ & $\mathbf{1 3 4}$ & $\mathbf{0 . 1 5}$ & $\mathbf{1 9 0}$ \\
$\operatorname{cs} 8$ & 0.72 & 334 & 0.34 & 54 & 0.14 & $\mathbf{2 1 2}$ & 0.24 & 178 \\
$\operatorname{cs} 9$ & 0.74 & 23 & 0.35 & 103 & 0.23 & 221 & 0.27 & 170 \\
$\operatorname{cs} 10$ & 0.91 & 60 & 0.41 & 140 & 0.29 & 221 & 0.27 & 159 \\
\hline
\end{tabular}
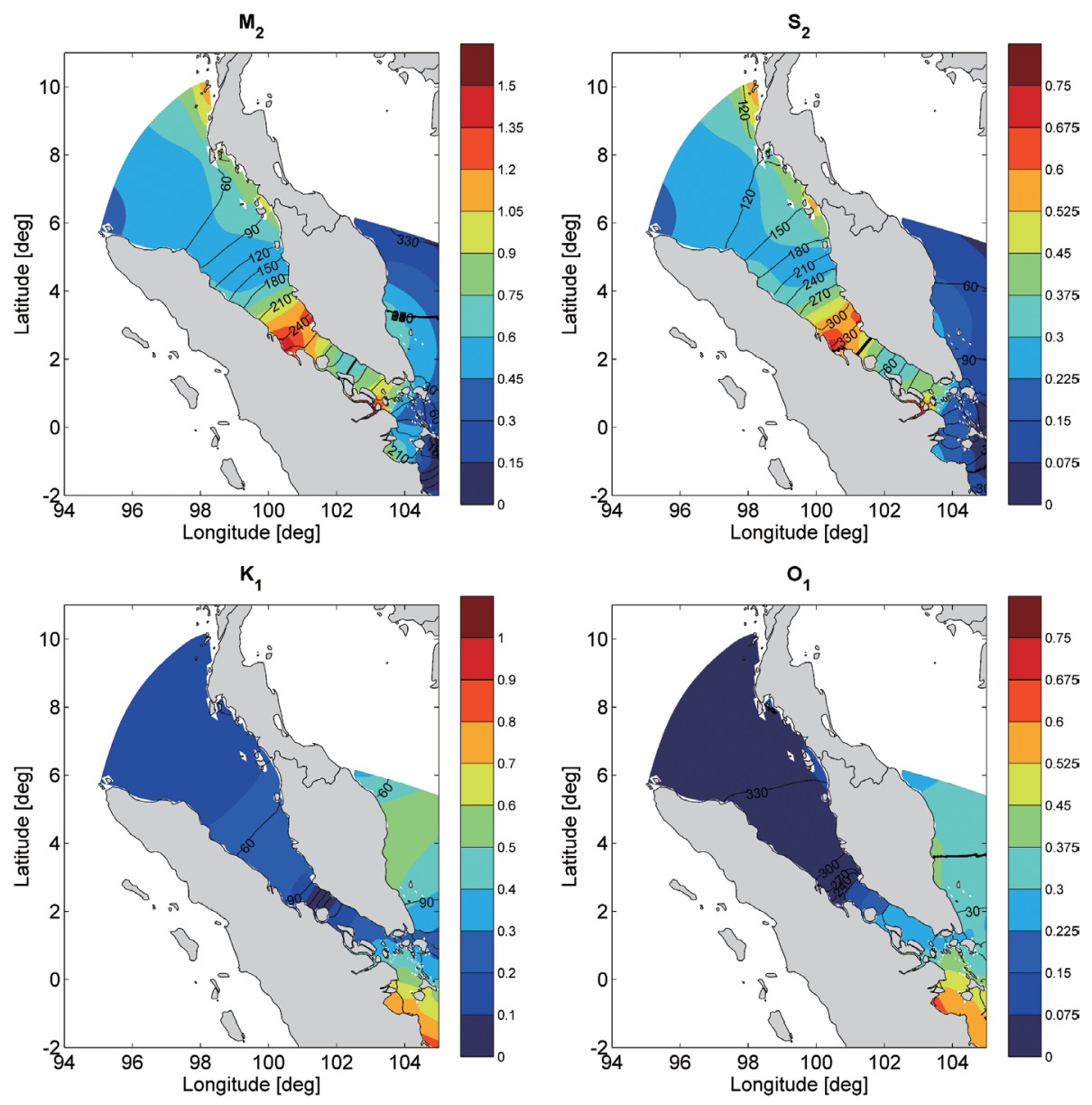

Fig. 3. Co-tidal map of $\mathrm{M}_{2}, \mathrm{~S}_{2}, \mathrm{~K}_{1}$, and $\mathrm{O}_{1}$ in Malacca Strait. 


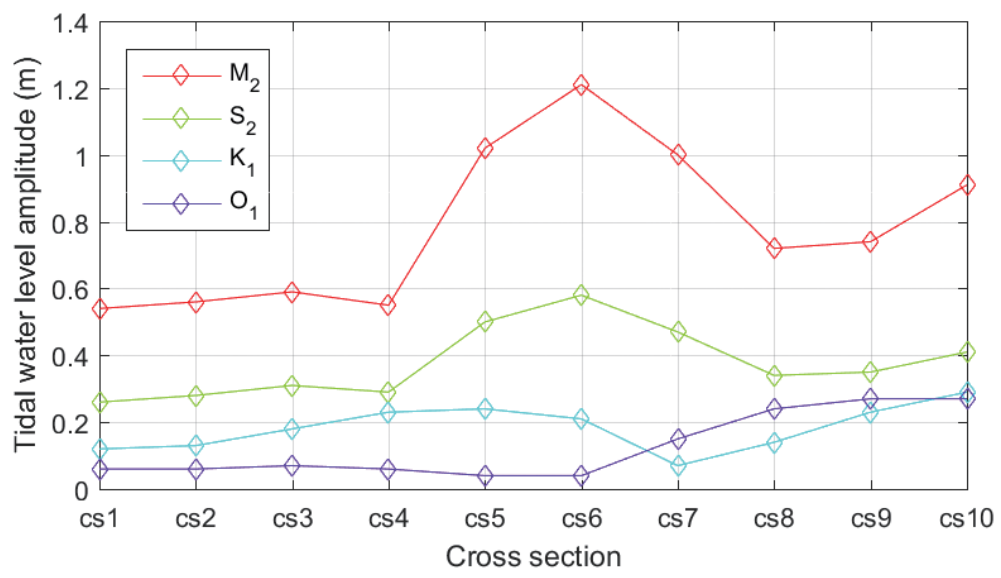

Fig. 4. Tidal water level amplitude of four main tidal constituents at the centre of each cross section.
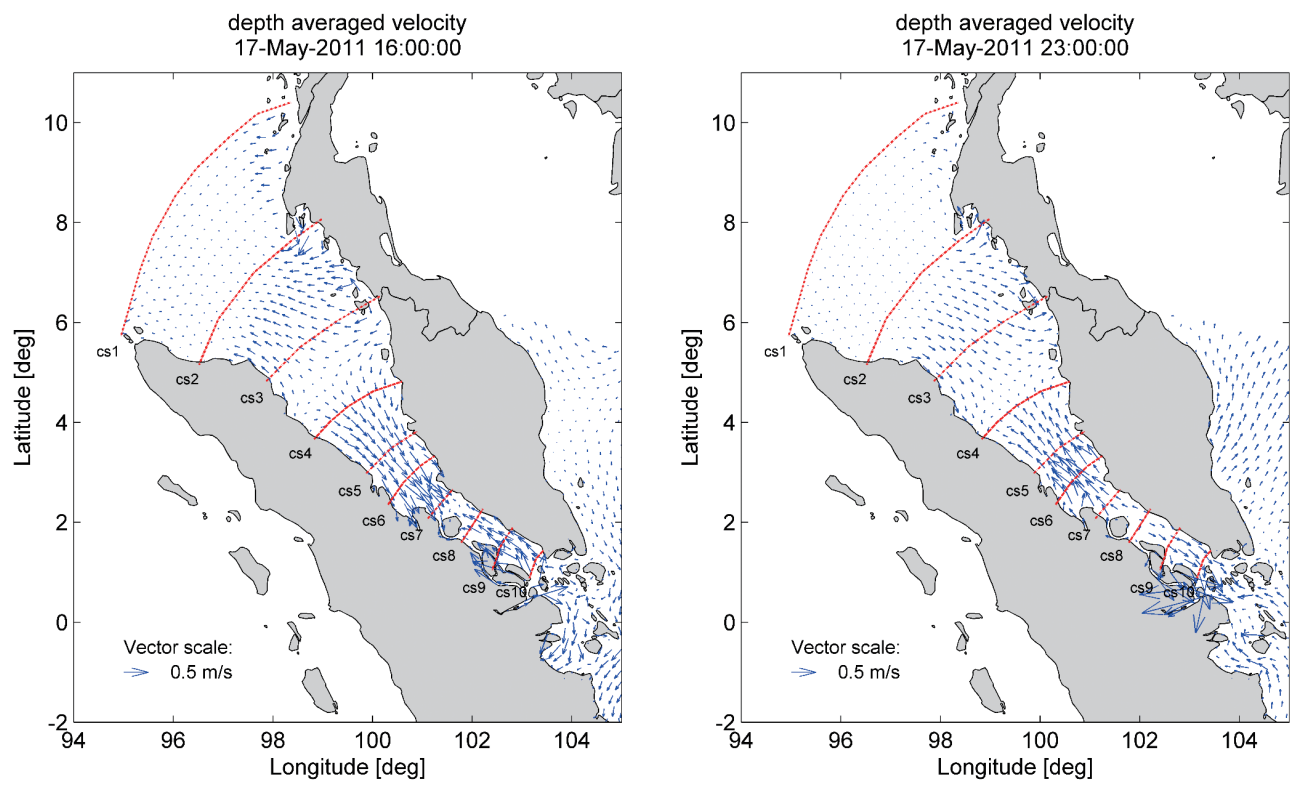

Fig. 5. Current vector field (blue) during flood tide (left) and ebb tide (right) with cross sections (red).

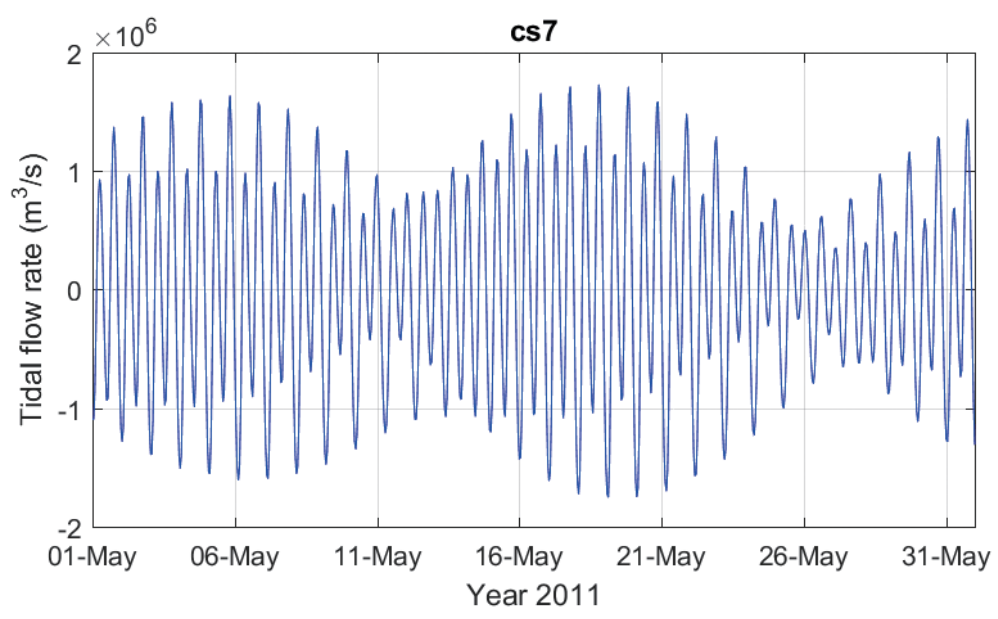

Fig. 6. One month simulated tidal flow rate time series at cross section cs7. 


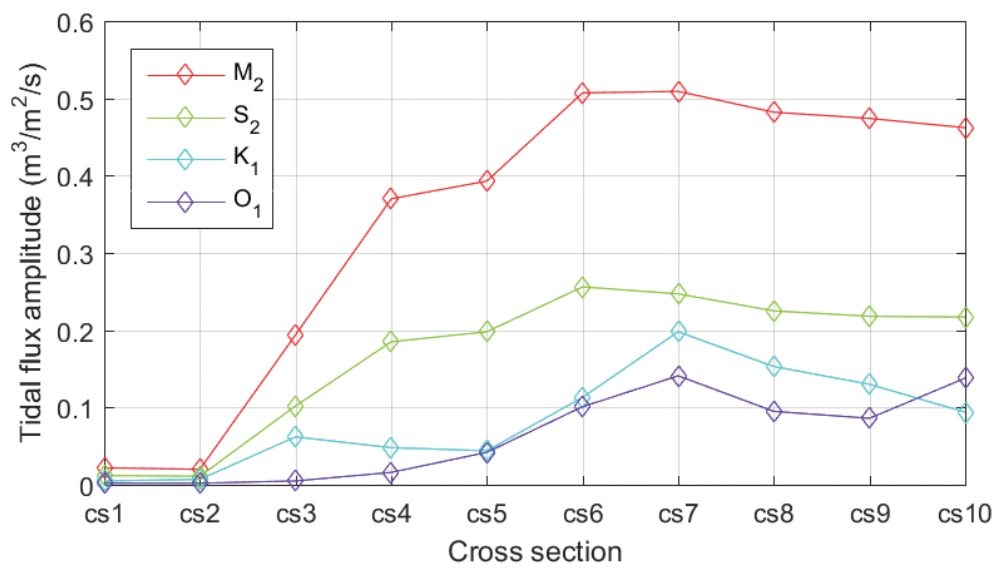

Fig. 7. Tidal flux amplitude of four main tidal constituents at each cross section.
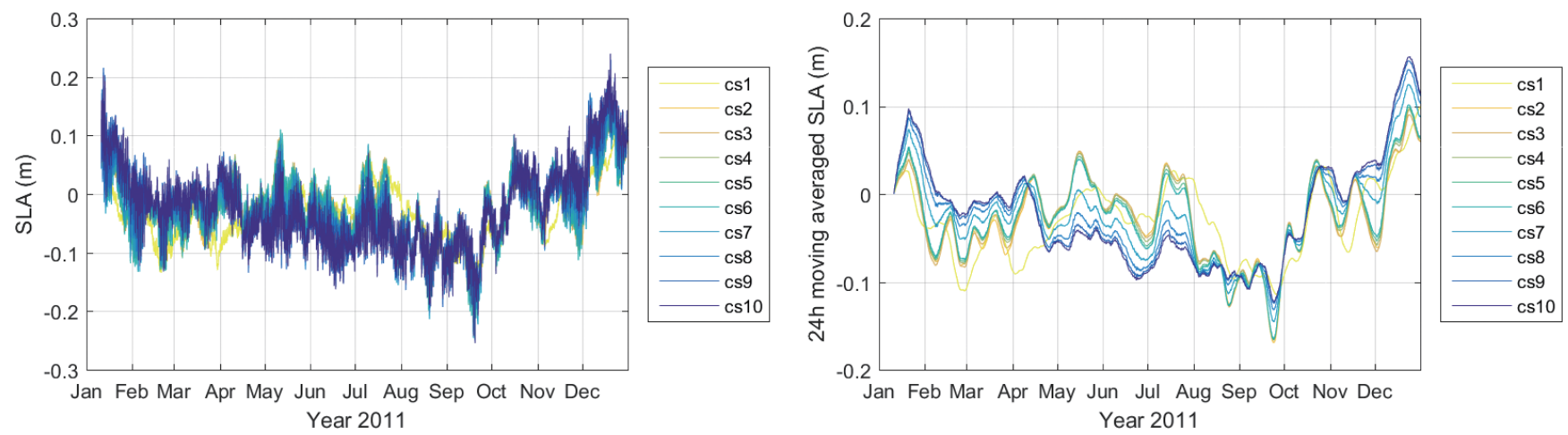

Fig. 8. One-year hourly SLA timeseries and its 24-hour moving averaged at centre of each cross section.

In Malacca Strait, both the diurnal and semi-diurnal tides have their local peak flux amplitudes near cs7; noting $\mathrm{O}_{1}$ originates from the southeast end of Malacca strait while $\mathrm{M}_{2}, \mathrm{~S}_{2}$, and $\mathrm{K}_{2}$ originate from the northwest end. This implies that cs7 is the confluence of the diurnal and semidiurnal tides which is known as the tidal mixing zone. This is also consistent with the result of the tidal water level analysis earlier in which significant changes in amplitude and phase of all four tidal constituents are found to be occurring near cs7 (Haditiar et al. 2020).

\subsection{Sea Level Anomalies Propagation}

In the previous chapters, tidal water level and flow rate in Malacca Strait have been examined in detail across different sections or zones in the strait. In this chapter, following the definition of computed SLA by Tay et al. (2016), we will assess the non-tidal barotropic forcing effect which are the SLA and their associated flow rate, in order words, the SLA propagation in Malacca Strait.

As the origin of SLA and seasonal behavior in Malacca Strait has already been studied in detail by Tay et al. (2016), the present paper will not focus on the SLA temporal varia- tion at individual locations. On contrary, the spatial changes of SLA will be of focus; in other words, the SLA changes between the cross sections will be analyzed.

Figure 8 presents the SLA hourly timeseries at the centre of all 10 cross sections and the same SLA timeseries but with a 24-hour moving average filter for better visual comparison of SLA at each cross section. Based on the findings of Tay et al. (2016) of spatial dependencies of multi-year satellite derived SLA, SLA behavior between cs 1 to cs6 is highly correlated which is also observed in the computed SLA in this paper, except for cs1 and is probably due to the open boundary numerical effect of the model. To see the spatial SLA dependencies and relative difference in Malacca Strait, the correlation coefficient and root mean squares difference [see Eq. (1)] between two adjacent cross sections are determined and presented Table 4. As mentioned earlier, the SLA at cs1 is affected by the numerical open boundary effect which explains the high RMSD and low correlation between cs1 and cs 2 and will be excluded from the following analysis. Low RMSD (less than $0.01 \mathrm{~m}$ ) and high correlation (greater or equal than 0.99 ) is observed from cs 2 to cs6. Slightly higher RMSD $(0.015-0.017 \mathrm{~m})$ and slightly lower correlation $(0.97-0.98)$ is observed from $\operatorname{cs} 8$ to $\operatorname{cs} 10$. 
Table 4. Root mean squared difference (RMSD) and correlation coefficient of SLA between two adjacent cross sections (numbers in bold indicate distinctive features or anomalies which are described and highlighted in the text).

\begin{tabular}{ccc}
\hline Adjacent cross sections & RMSD (m) & Correlation coefficient \\
\hline cs1 and cs2 & 0.043 & 0.70 \\
cs2 and cs3 & 0.007 & 0.99 \\
cs3 and cs4 & 0.009 & 0.99 \\
cs4 and cs5 & 0.009 & 0.99 \\
cs5 and cs6 & 0.006 & 1.00 \\
cs6 and cs7 & $\mathbf{0 . 0 2 7}$ & $\mathbf{0 . 9 1}$ \\
$\operatorname{cs} 7$ and cs8 & $\mathbf{0 . 0 2 2}$ & $\mathbf{0 . 9 4}$ \\
$\operatorname{cs} 8$ and $\operatorname{cs} 9$ & 0.015 & 0.98 \\
$\operatorname{cs} 9$ and $\operatorname{cs} 10$ & 0.017 & 0.97 \\
\hline
\end{tabular}

High RMSD (0.022 - $0.027 \mathrm{~m})$ and low (0.91 - 0.94) is observed between cs6 and cs8. This implies that the propagation of SLA from Andaman Sea and Singapore Strait is obstructed in the area between cs6 and cs7 where the tidal mixing zone is (see section 3.1).

Using the same method of studying tidal propagation earlier, the propagation of SLA can also be done by analyzing its associated flow rate and flux. Following the same definition of SLA in Eq. (4), the SLA associated flow rate can also be defined as follows.

$$
\begin{aligned}
& \text { FlowRate }_{(S L A)}= \\
& \text { FlowRate }_{(\text {tide and Non-tidal forcing) }}-\text { FlowRate }_{(\text {tide })}
\end{aligned}
$$

Where by FlowRate $_{(S L A)}$ is the SLA associated flow rate, FlowRate $_{\text {(tide and non-tidal forcing) }}$ is the flow rate simulated using both tide and non-tidal forcing, and FlowRate $_{(\text {tide }}$ is the flow rate simulated using tide forcing only. Figure 9 presents the SLA associated flow rate timeseries at all cross sections. As cs 3 has the highest range of flow rate compared to the other cross sections. Therefore, to evaluate the SLA propagation through each cross section properly, flux (i.e., flow rate per unit area) at the cross sections is analyzed.

Figure 9 also presents the SLA associated flux timeseries at all cross sections and the same SLA associated flux timeseries but with a 24-hour moving average filter for better visual comparison of flux at each cross section. It is shown that the flux at cs10 is the highest in both directions among all cross sections which means that there is a strong local non-tidal flow exchange where both Singapore Strait and Malacca Strait merge. Using the same approach for analyzing the SLA, calculation of the correlation coefficient and root mean squared difference of SLA associated flux between two adjacent cross sections will be carried out to see their spatial dependencies and relative difference in the strait (see Table 5).
High RMSD values (more than or equal to $0.015 \mathrm{~m}^{3} \mathrm{~m}^{-2} \mathrm{~s}^{-1}$ ) are observed at two zones: (1) between cs5 and cs7, and (2) between cs9 and cs10, with the latter showing the most significant difference in SLA associated flux between the adjacent cross sections. However, the correlation coefficient in these zones are relatively high (0.96-0.98), and the lowest correlation of 0.90 is observed between cs 3 and cs 4 though this correlation value is typically considered high. Considering the cross-sectional area of cs 3 and cs 4 are significantly larger (about 2 times and more) than cs 5 to cs 10 , this means the assumption of flow direction uniformity may not be as strongly applicable for cs 3 and cs 4 as to the smaller cross sections. Therefore, the slightly lower correlation values at cs 3 and cs 4 can be considered to be sufficiently well correlated.

To quantify the volume of water that passes through each cross section (per unit area) over a certain period time, one can first determine the volume per unit area by multiplying the flux with the time interval quantity of the flux timeseries and make a summation of this so-called net flux volume $\left(\mathrm{m}^{3} \mathrm{~m}^{-2}\right)$ timeseries over the period of interest [see Eq. (5)].

$$
\begin{aligned}
& \text { NetFluxVolume }_{(\text {time period) }}= \\
& \sum_{\text {(time period) }}(\text { Flux } \times \text { TimeInterval })
\end{aligned}
$$

Figure 10 presents the net SLA associated flux volume, net southeastward (positive) SLA associated flux volume and net northwestward (negative) SLA associated flux volume at each cross section over one year. It is noted that the summation of net southeastward flux and net northwestward flux will result in the net flux. It is shown that the net flux volume at all cross sections is negative over one year, which implies that there is a northwestward net flux transport in the year 2011.

Figure 10 also shows significant change of net flux 

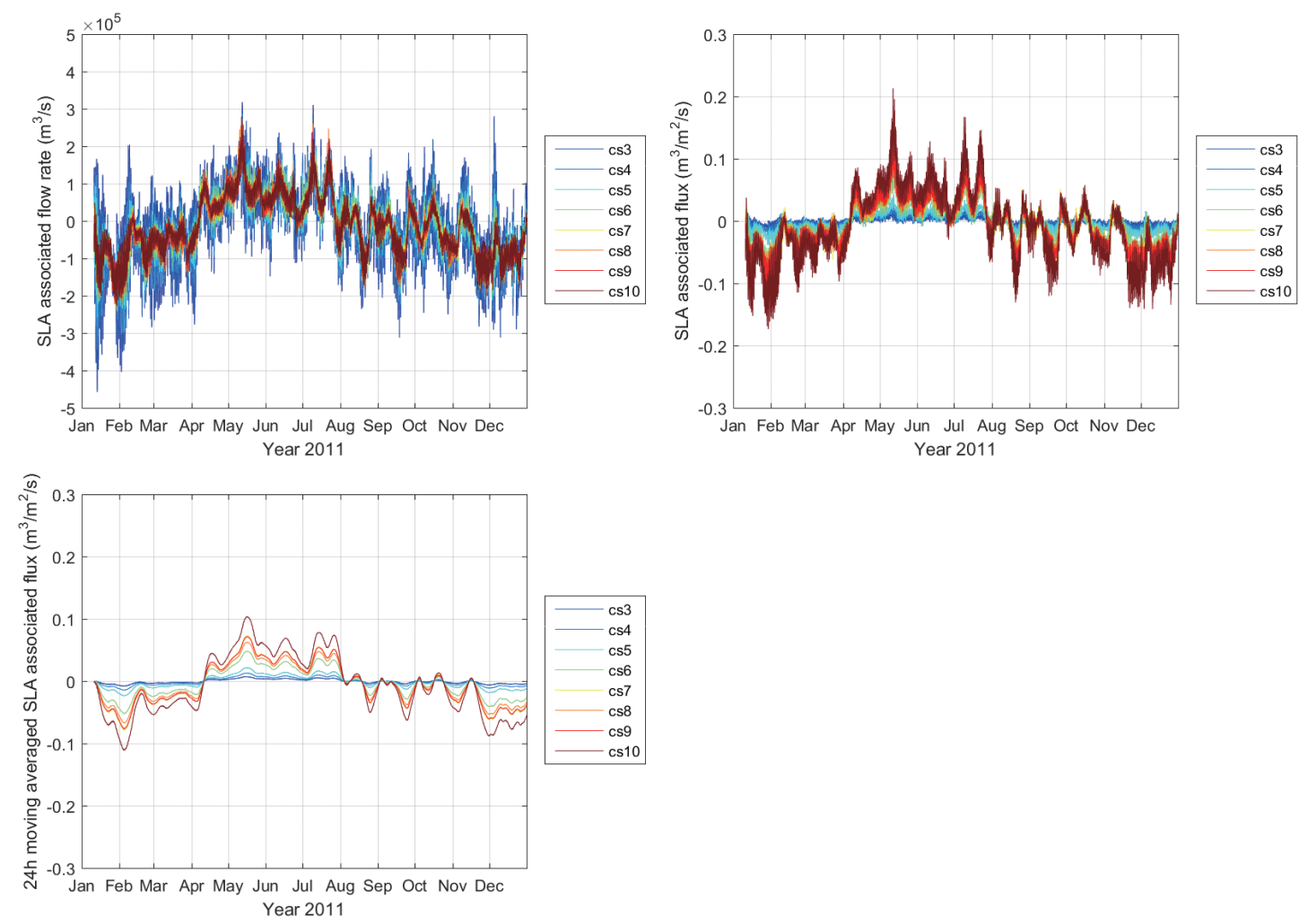

Fig. 9. One-year SLA associated flow rate, flux and a 24-hour moving averaged associated flux timeseries at each cross section (positive indicates southeastward progression).

Table 5. Root mean squared difference (RMSD) and correlation coefficient of SLA associated flux between two adjacent cross sections.

\begin{tabular}{ccc}
\hline Adjacent cross sections & $\mathbf{R M S D}\left(\mathbf{m}^{\mathbf{3}} \mathbf{~}^{-\mathbf{2}} \mathbf{s}^{-1}\right)$ & Correlation coefficient \\
\hline cs3 and cs4 & 0.004 & 0.90 \\
$\operatorname{cs} 4$ and cs5 & 0.006 & 0.95 \\
$\operatorname{cs} 5$ and cs6 & $\mathbf{0 . 0 1 5}$ & 0.98 \\
$\operatorname{cs} 6$ and cs7 & $\mathbf{0 . 0 1 6}$ & 0.96 \\
$\operatorname{cs} 7$ and $\operatorname{cs} 8$ & 0.010 & 0.97 \\
$\operatorname{cs} 8$ and $\operatorname{cs} 9$ & 0.009 & 0.98 \\
$\operatorname{cs} 9$ and $\operatorname{cs} 10$ & $\mathbf{0 . 0 2 2}$ & 0.97 \\
\hline
\end{tabular}

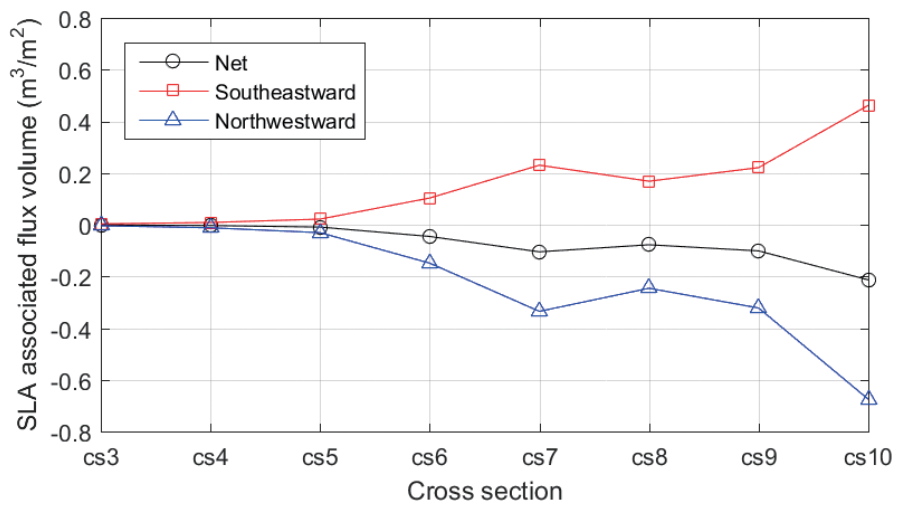

Fig. 10. Net SLA flow volume at each cross section averaged over one year (positive indicates southeastward progression). 
volume in both directions occurs at two zones: (1) between cs5 and cs7, and (2) between cs9 and cs 10 . This is consistent with the flux RMSD values shown earlier (Table 5). In a way, this is similar to the spatial variation of tidal water level and flux amplitude in which distinct features of each tidal constituents are observed near cs7. The tidal mixing zone (near cs7) is playing a role in the propagation of SLA and its associated flux in both directions.

As for the zone near cs10 where significant change of SLA and its associated flux are also observed, no clear conclusion can be drawn at this point of time. As Singapore Strait is also known to be a confluence zone of tides from three major seas in the region, i.e., Andaman Sea, South China Sea and Java Sea (Pugh 1996; Chen et al. 2005; Van Maren and Gerritsen 2012) and cs10 is the closest to Singapore Strait, a further study that also includes the tidal and SLA fluxes through Singapore Strait may be required to bring more insights to SLA propagation dynamics in this zone.

\section{CONCLUSION}

In this paper, tide and SLA propagation in Malacca Strait is evaluated using results of a barotropic well-calibrated and validated numerical model water level and flow rate. The strait is divided into nine zones portioned by 10 cross sections. In the first part of the paper, amplitudes of four main tidal constituents $\mathrm{M}_{2}, \mathrm{~S}_{2}, \mathrm{~K}_{1}$, and $\mathrm{O}_{1}$ are compared between each cross section to investigate the change of amplitude for each tidal wave as it propagates through the strait. The semi-diurnal tides propagate from the Andaman Sea and dominate the whole strait, with their increase of amplitude begins when they approach the break of Sunda Shelf in front of Andaman Sea, and both semi-diurnal tidal waves propagate through Malacca Strait at a relatively consistent speed. The diurnal tides originate from two different ends, in other words, opposite directions, with $\mathrm{O}_{1}$ propagating northwestward from Singapore Strait. It has been noted that the change of tidal water level amplitude or phase mostly occur in the zone between cs 6 and cs8. For the tidal flux amplitudes, it is shown that both diurnal and semi-diurnal tides have their local peak near cs7, which implies that cs7 is close to the confluence point of the tides and is known as the tidal mixing zone.

In the second part of the paper, the one-year modelled SLA is analyzed by computing the RMSD and correlation coefficient between two adjacent cross sections to assess if there is any relative difference It has been found that the RMSD and correlation are relatively poorer from cs 6 to cs 8 , where the tidal mixing zone is. This implies that the propagation of SLA from Andaman Sea and Singapore Strait is obstructed by the tidal mixing zone. For the SLA associated flux, there are two zones of relatively high RMSD; one is between cs 5 and cs 7 , while another between cs 9 and cs 10 , with the latter (the closest to Singapore Strait) showing signifi- cant RMSD. Further assessment of SLA associated flux is carried out by computing the net flux volume through each cross section over a period of time. It is shown that the net flux volume at all cross sections is negative over one year, which implies that there is a northwestward net flux transport in the year 2011. When the net flux volume in southeastern and northwestern direction are computed separately for each cross section, the significant zone of change in net flux volume in both directions occur at the same two zones where relatively high SLA difference between cross sections is observed. In a way, this is similar to the spatial variation of tidal water level and flux amplitude in which distinct features of each tidal constituents are observed near cs7. The tidal mixing zone (near cs7) is playing a role in the propagation of SLA and its associated flux in both directions.

While the annual volume flux numbers are miniscule, this paper has shown that water level (or SLA) and its associated flux through Malacca Strait, especially tide induced, show different propagation patterns because of the complexity of the driving processes. These results highlight the need to include flux analysis in this area as it is vital for water volume transport that contribute to the change of local temperature, salinity and biochemical properties as these are the parameters that govern the health of the ecosystems and natural resources in Malacca Strait.

Acknowledgements The first author would like to acknowledge the support and contributions of the Coastal Engineering Research Group, Ocean Engineering Program, Faculty of Civil and Environmental Engineering, Institut Teknologi Bandung. This study was partially funded by the National Research Foundation, Prime Minister's Office, Singapore under its Marine Science R\&D Programme (MSRDP-P04).

\section{REFERENCES}

Amiruddin, A. M., Z. Z. Ibrahim, and S. A. Ismail, 2011: Water mass characteristics in the Strait of Malacca using ocean data view. Research Journal of Environmental Sciences, 5, 49-58, doi: 10.3923/rjes.2011.49.58. [Link]

Bonar, P. A. J., A. M. Schnabl, W.-K. Lee, and T. A. A. Adcock, 2018: Assessment of the Malaysian tidal stream energy resource using an upper bound approach. $J$. Ocean Eng. Mar. Energy, 4, 99-109, doi: 10.1007/ s40722-018-0110-5. [Link]

Chen, H., P. Malanotte-Rizzoli, T.-Y. Koh, and G. Song, 2014: The relative importance of the wind-driven and tidal circulations in Malacca Strait. Cont. Shelf Res., 88, 92-102, doi: 10.1016/j.csr.2014.07.012. [Link]

Chen, M., K. Murali, B.-C. Khoo, J. Lou, and K. Kumar, 2005: Circulation modelling in the strait of Singapore. J. Coast. Res., 215, 960-972, doi: 10.2112/04-0412.1. [Link] 
Chong, H.-Y. and W.-H. Lam, 2013: Ocean renewable energy in Malaysia: The potential of the Straits of Malacca. Renew. Sust. Energ. Rev., 23, 169-178, doi: 10.1016/j. rser.2013.02.021. [Link]

Friedrichs, C. T. and D. G. Aubrey, 1994: Tidal propagation in strongly convergent channels. J. Geophys. Res., 99, 3321, doi: 10.1029/93JC03219. [Link]

Haditiar, Y., M. R. Putri, N. Ismail, Z. A. Muchlisin, M. Ikhwan, and S. Rizal, 2020: Numerical study of tides in the Malacca Strait with a 3-D model. Heliyon, 6, e04828, doi: 10.1016/j.heliyon.2020.e04828. [Link]

Hii, Y. S., A. T. Law, N. A. M. Shazili, M. K. Abdul Rashid, H. Mohd Lokman, F. M. Yusoff, and H. M. Ibrahim, 2006: The Straits of Malacca: Hydrological parameters, biochemical oxygen demand and total suspended solids. Journal of Sustainability Science and Management, 1, 1-14.

Ibrahim, Z. Z. and T. Yanagi, 2006: The influence of the Andaman Sea and the South China Sea on water mass in the Malacca Strait. La Mer, 44, 33-42.

Kurniawan, A., S. K. Ooi, S. Hummel, and H. Gerritsen, 2011: Sensitivity analysis of the tidal representation in Singapore Regional Waters in a data assimilation environment. Ocean Dyn., 61, 1121-1136, doi: 10.1007/ s10236-011-0415-6. [Link]

Kurniawan, A., S. K. Ooi, and V. Babovic, 2014: Improved sea level anomaly prediction through combination of data relationship analysis and genetic programming in Singapore Regional Waters. Comput. Geosci., 72, 94104, doi: 10.1016/j.cageo.2014.07.007. [Link]

Kurniawan, A., S. H. X. Tay, S. K. Ooi, V. Babovic, and H. Gerritsen, 2015: Analyzing the physics of non-tidal barotropic sea level anomaly events using multi-scale numerical modelling in Singapore regional waters. J. Hydro-environ. Res., 9, 404-419, doi: 10.1016/j. jher.2014.10.005. [Link]

Lesser, G. R., J. A. Roelvink, J. A. T. M. van Kester, and G. S. Stelling, 2004: Development and validation of a three-dimensional morphological model. Coast. Eng., 51, 883-915, doi: 10.1016/j.coastaleng.2004.07.014. [Link]
Luu, Q. H., P. Tkalich, and T. W. Tay, 2015: Sea level trend and variability around Peninsular Malaysia. Ocean Sci., 11, 617-628, doi: 10.5194/os-11-617-2015. [Link]

Naeije, M. C., E. J. O. Schrama, E. N. Doornbos, and R. Scharroo, 2006: The role of RADS in building the 15year Altimeter record. Proceedings of the Symposium on 15 Yaers of Progress in Radar Altimetry, ESA, Venice, 6 pp.

Pugh, D. T., 1996: Tides, Surges and Mean Sea-Level (Reprinted with Corrections), John Wiley \& Sons, Ltd., Chichester, UK, 486 pp.

Rizal, S. and J. Sündermann, 1994: On the M2-tide of the Malacca Strait: A numerical investigation. Dtsch. Hydrogr. Zeitschrift., 46, 61-80, doi: 10.1007/ bf02225741. [Link]

Rizal, S., I. Setiawan, T. Iskandar, Y. Ilhamsyah, M. A. Wahid, and M. Musman, 2010: Currents simulation in the Malacca Straits by using three-dimensional numerical model. Sains Malaysiana, 39, 519-524.

Tan, C. K., J. Ishizaka, S. Matsumura, F. M. Yusoff, and M. I. H. Mohamed, 2006: Seasonal variability of SeaWiFS chlorophyll a in the Malacca Straits in relation to Asian monsoon. Cont. Shelf Res., 26, 168-178, doi: 10.1016/j.csr.2005.09.008. [Link]

Tay, S. H. X., A. Kurniawan, S. K. Ooi, and V. Babovic, 2016: Sea level anomalies in straits of Malacca and Singapore. Appl. Ocean Res., 58, 104-117, doi: 10.1016/j.apor.2016.04.003. [Link]

Thia-Eng, C., I. R. L. Gorre, S. A. Ross, S. R. Bernad, B. Gervacio, and M. C. Ebarvia, 2000: The Malacca Straits. Mar. Pollut. Bull., 41, 160-178, doi: 10.1016/ S0025-326X(00)00108-9. [Link]

Van Maren, D. S. and H. Gerritsen, 2012: Residual flow and tidal asymmetry in the Singapore Strait, with implications for resuspension and residual transport of sediment. J. Geophys. Res., 117, doi: 10.1029/2011JC007615. [Link]

Van Rijn, L. C., 2011: Analytical and numerical analysis of tides and salinities in estuaries; Part I: Tidal wave propagation in convergent estuaries. Ocean Dyn., 61, 1719-1741, doi: 10.1007/s10236-011-0453-0. [Link] 